\title{
Memory Strategies and Vocabulary Learning Strategies: Implications on Teaching and Learning Vocabulary
}

\author{
Suhair Saadaldeen Al-Faris ${ }^{1} \square$ and Basim Yahya Jasim ${ }^{2}$ \\ ${ }^{1}$ Ph.D. Student, Department of Business Administration, Cihan University-Erbil /KRG, Iraq \\ ${ }^{2}$ College of Arts, University of Mosul / Iraq \\ $\square$ Corresponding Author: Suhair Saadaldeen Al-Faris, E-mail: suhair.saadaldeen@cihanuniversity.edu.iq
}

\begin{tabular}{|c|c|}
\hline ARTICLE INFORMATION & ABSTRACT \\
\hline Received: 08 September 2021 & Memory Strategies (MSs) and Vocabulary Learning Strategies (VLSs) have been studied \\
\hline Accepted: 05 October 2021 & in many studies through the years. The purpose of the current study is to shed light on \\
\hline Published: 22 October 2021 & the fundamental role of Memory strategies and Vocabulary Learning Strategies \\
\hline DOI: $10.32996 / j h s s s .2021 .3 .10 .2$ & $\begin{array}{l}\text { suggested in vocabulary teaching and learning. Thus, the study has presented a } \\
\text { comprehensive overview of both strategies by selecting the most prominent ones. In }\end{array}$ \\
\hline KEYWORDS & addition, it offered a thorough demonstration of vocabulary background in general \\
\hline $\begin{array}{l}\text { Memory Strategies, } \\
\text { Vocabulary Learning Strategies, } \\
\text { Vocabulary, } \\
\text { teaching/ learning vocabulary }\end{array}$ & $\begin{array}{l}\text { and vocabulary in English for Specific Purposes (ESP) in particular. The research } \\
\text { question states: Can Memory Strategies (MSs) and Vocabulary Learning } \\
\text { Strategies(VLSs) be integrated and applied in teaching and learning vocabulary? In } \\
\text { conclusion, the study tries to make it clear for the reader, teachers, and learners, that } \\
\text { merging (MS) and (VLS) can be utilized for this objective. The implication of the study } \\
\text { lies in providing the reader with a grounded platform for selecting what is suitable in } \\
\text { a teaching/learning setting. }\end{array}$ \\
\hline
\end{tabular}

\section{Introduction}

Learners of a foreign language keep struggling with vocabulary along the process of language learning. The task may appear to be simple but because of its steady nature the difficulties of learners' experience in remembering the huge number of lexis, its significance is undeniable (Decaricco, 2001:290). Danesi (2003) stated that only 4\% of learners' brain is activated when following traditional language teaching and to ensure better retention, a deeper level of processing should be applied for new words. Nation (2004) asserted that words are the basic component of any language for their vital function in labeling objects, actions, and thoughts. They are considered central to language due to their great importance for learners' comprehending. Still, vocabulary is the most unmanageable component, and learning it is a challenging experience. Hatch and Brown (1995) emphasize the outstanding role of vocabulary knowledge in S/F language learning. To facilitate vocabulary learning, teaching vocabulary learning strategies has been suggested (Nemati,2009).

Language learning strategies occupied the focus of researchers and vocabulary learning has attracted attention since the mid1980s. In the 1990s, English as a second language (ESL) researchers were concerned with vocabulary by a number of publications as well as the ESL pedagogy and research (Wei, For Rubin (1987:22), language learning strategies contribute to language system development that learners construct and affect learning directly. Thus, considerable approaches, strategies, techniques, exercises, and practices have been suggested in the field of teaching vocabulary. Hulstjin, (1993, cited in Morin and Goebel 2001) stressed that teaching vocabulary should not only include teaching particular words but is also supposed to equip learners with necessary strategies for expanding their vocabulary knowledge.

Before providing an elaborated overview of literature or these strategies, a spotlight is shed on the literature development of the vocabulary importance in general and on technical vocabulary in particular with respect to teaching and learning.

Copyright: (C) 2021 the Author(s). This article is an open access article distributed under the terms and conditions of the Creative Commons Attribution (CC-BY) 4.0 license (https://creativecommons.org/licenses/by/4.0/). Published by Al-Kindi Centre for Research and Development, London, United Kingdom. 


\section{Literature Review : (Vocabulary: Definitions and Significance )}

Vocabulary is viewed as the glue that holds stories, ideas, and content together, making comprehension accessible for children (Rupley, Logan \& Nichols 1998:339). Clark (1993) also argued that without vocabulary, it will be uneasy for us to communicate and express thoughts about people, locations, or things, as well as activities, relations, and states. For Snow, Burns, \& Griffin (1998), vocabulary or lexicon represents information stored in memory comprising pronunciation and meanings of words. Beck and Mckeown (1991) pointed out that it is not the case that one either knows or does not know a word. Rather, knowledge of a word should be viewed in terms of the extent or degree of knowledge that "people can possess".

Vocabulary can also be defined as a collection of words that somebody understands. According to Nunan (2006), someone who understands terminology effectively would have an impact on the process of good communication. It implies that studying English vocabulary can develop a better mindset and improve communication skills.

Acquiring vocabulary is a fundamental part of communicating meaning (Wilkins, 1972). In mastering a language, according to Oxford (1990:39) "Vocabulary is by far the most sizeable and unmanageable component in learning any language, whether a foreign or one's mother tongue". Wilkins (1972:111) and Mediha and Enisa (2014) put more emphasis on vocabulary than on grammar asserting that while with no grammar little can be conveyed, without vocabulary nothing at all can be conveyed and communication cannot take place.

Vocabulary is the core of the language, having great importance to language learners. Words are considered the basic bricks of a language because they name actions, objects, ideas. Without them, we cannot convey aimed meaning (Hatch \& Brown, 1995). The significant role of the knowledge in S/FLL vocabulary was the hot topic of recent theories and researches and a considerable number of approaches, exercises and techniques, and strategies have been presented in this field to teach vocabulary.

Vocabulary is the base of any language holding the content of any idea, concept, thought. Humans with different languages can communicate easily with an average knowledge of vocabulary regardless of grammar. It is the first step of language learning. When Teaching a language, most teachers focus on vocabulary to build up a solid base in learning.

\subsection{Vocabulary Learning}

Vocabulary in learning a language is essential to master since it enables learners in overcoming language learning challenges. Krashen (1981:12) reported that learning vocabulary is part of learning a language. It is a fundamental step for the communication and acquisition process. Vocabulary is the core of language and is of great importance to language learners (Zimmerman,1998:33). The importance of vocabulary does not only lie in establishing cognitive systems of language skills and linguistic knowledge, but also in assisting the communicative and comprehensive interaction (Coady \& Huckin, 1997).

Nation (2001) stressed that general learning strategies comprise language learning strategies which in turn comprise vocabulary learning strategies. Learners of foreign languages keep struggling with vocabulary along the process of language learning. The task may appear to be simple but because of its steady nature, the difficulties of learners' experience in remembering the huge number of lexis experienced still exist and continues. Decaricco (2001) agreed that its importance is undeniable being the core of the argument for language acquisition, regardless of whether the language is first or second.

For starters, some of these words may be commonplace vocabulary that students are already familiar with yet have a specific meaning in their profession. These new meanings can be difficult to acquire because the learners' vocabulary already contains ordinary meanings (Coxhead, 2013). Furthermore, some of the technical terms may necessitate field-specific understanding. As a result, learners should be trained in VLS to deal with these obstacles in learning specialized lexical items (Nation, 2001).

Vocabulary is also vital in the method of language teaching and teaching English as a Foreign language in particular. The ground for that is, without adequate vocabulary, it would be hard for learners to clearly grasp and comprehend a language and easily express ideas they intend to communicate. Dudley-Evans \& John (1998:81) maintained that in certain contexts it is the duty of the ESP teacher to make sure that learners understand technical vocabulary. It is important that both teachers and learners consider that this vocabulary acts as carriers of content for an exercise not as real content. Hence, a considerable number of approaches, exercises, techniques, and strategies have been proposed to teach vocabulary (Hatch and Brown,1995).

\subsection{Vocabulary Learning}

Baddeley (1999:88) maintained that very little of what we learn in actual life includes meaningless information therefore the memory psychology for nonsense has a limited value. Recently, there have been much more concerns in using actual words rather than using nonsense syllables to conduct experiments on memory. Needless to say that words differ in the way we remember them, some are easy to remember and some are not. Baddeley has also pointed that "what (John Harris, 1980) proved in his study 
about the mnemonics aids, are all external ones such as diaries, calendars, lists, and timers. Alternatively, he conducted what he called "never-fail system to help you remember".

The task is difficult so both teachers and students try to search for the best and most efficient process to learn it. Teachers can present vocabulary to students either deliberately or unconsciously. It is proposed that actual contact with the target language and extensive reading (thus incidental vocabulary learning) guarantees learners' vocabulary progress (Nation, 2001; Oxford, 2001; Oxford and Scarcella, 1994). In the same vein, Ellis (1997) states that an idealistic source for second language vocabulary learning from context is reading (Višnja, 2006). However, the new approach of teaching vocabulary holds that vocabulary learning can be boosted when the attention of the learners is guided consciously towards vocabulary items as well as to the strategies followed to learn it (Nation, 2001).

A number of taxonomies of vocabulary learning strategies emerged in the field of language acquisition, remarkably, Gu and Johnson (1996), Schmitt (1997), and Nation (2001) comprising different types of strategies that are suitable for learners' learning styles, age, gender, attitude, motivation, personality, etc.

Memory strategies, also traditionally called 'mnemonics', indicate retaining strategies of new words utilizing some imagery or grouping (Schmitt, 2000), hence, they assist learners to combine a new word with information already familiar to them (Oxford, 1990). Schmitt (1997) has maintained that "while studying the use of strategies of vocabulary learning for different age groups, that the younger the learners, the simpler the strategies which are used while adult learners use 'deeper' mental processing strategies which require strategy like the ones of imaging the word's meaning. In other words, teachers' concern is not only to teach learners, vocabulary in specific but to teach them how to learn vocabulary i.e. to teach them strategies of vocabulary learning and the way they use them efficiently(ibid).

\section{Memory Strategies for Vocabulary Learning}

Memory strategies (MSs) are considered as one of the most effective tools in the process of vocabulary learning due to their extreme power as mental tools. Oxford (1990) referred to memory strategies as encompassing activities to enhance remembering and retrieving new knowledge such as keywords, acronyms, images, etc. They help learners combine second language L2 items with the new information. Memory strategies are proposed as simple rules to arrange information in human memory. They are defined as "those techniques which help learners 'store' specific information and then retrieve it when needed" (Oxford 1990:38). When new information is rehearsed through Memory Strategies, it will be transferred to LTM. Heuer (1999:25) presented a relating similar definition. For him, MS is a "means of organizing or encoding information for him the purpose of making it easier to remember". Schmitt (1997: 216) suggested another definition that combines the word with some knowledge that is previously stored and learned by activating some form of imagery or grouping. Heuer $(1999: 23,24)$ reported that new information is transformed from short-term memory to long-term memory by associating it with already existing schema in memory.

Scholars carried out a number of experiments to determine the most applicable MS to different variables. Bower, Clark, Lesgold, and Winzenz, (1969) agreed that most people find that organized items which act as a hierarchy (top panel) are much easier to remember than the others, despite the fact that it is quite possible to organize the second collection of items in the same way as the first. Subsequent work in enhancing memory has emphasized the importance of organizing learning.

Mnemonics as MS is traditionally known, are used to support remembering when connecting new information with already existing words and images (Levin, 1983; Mastropieri, Scruggs, \& Fulk, 1990).

Macaro (2001:118) pointed out that MS functions by "processing" vocabulary items in the "working memory". Thus it can be stored and retrieved from the long-term memory. He added that the strategies adopted would be similar to the way it was stored for retrieving (accessing information when needed) the piece of language. Furthermore, Bellezza (1981:249) posited that frequently used MS aid learning and recalling of L2 material.

Thompson (1987) was of the view that the importance of mnemonic techniques comes from memorization which is the base of language learning by which information is retrieved. Thompson (1987:43) pointed that these techniques enhance retrieval because they assist learners in faster learning and better recalling. What is more, most language learning relies on memorization and retrieval of information. So, the role of mnemonics is to integrate new knowledge with the cognitive units which already exist in mind. They could be adapted to learners according to their learning differences. Thompson (1987) added, "Most users indicate that they enjoy using these techniques". Also Wang and Thomas (1996:104)

\subsection{Taxonomies of Memory Strategies}


reported that MS enhances learning abstract words as they help learners relate abstract information to something more familiar and make meaningful associations between pieces of information stored in their memory.

Scholars have different approaches to classifying memory strategies. These strategies are similar in concept but different in the way presented, coined, and tackled by each scholar. They presented these strategies differently but with intense concentration on the outcome. Oxford's (1990), Thompson's (1987), Gu and Johnson's (1996), and Macaro's (2001) are the most distinguished.

\subsubsection{Oxford's (1990) Taxonomies}

Oxford (1990:60) classified memory strategies into four divisions: namely; Creating mental linkage, applying images and sounds, Reviewing well, and Employing actions. Figure 1. demonstrates these strategies with their sub-divisions. The author should clearly explain the important conclusions of the research highlighting their significance and relevance.

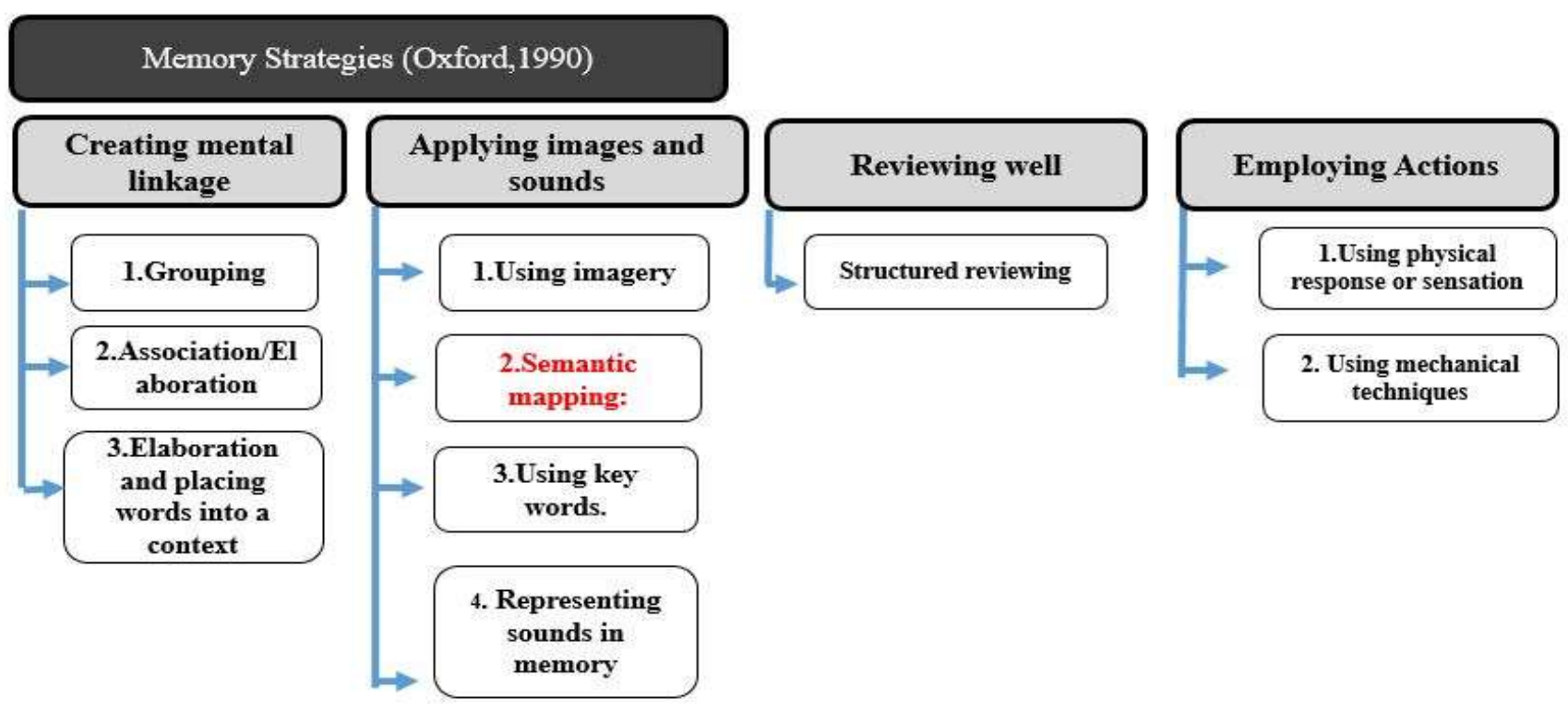

Note: Figure 1.: by Oxford, R. L. (1990). Language learning strategies: What every teacher should know. Boston : Heinle and Heinle Publishers.

Each one of these four sets has sub-divisions. Creating mental linkage is achieved by applying the strategies of grouping: by classifying or sub-classifying vocabulary into meaningful bunches in order to decrease the number of unrelated items either mentally or in writing in order to make the input easier to remember by reducing the number of discrete elements. A group can be types of words(e.g. nouns, verbs), topic (e.g. words about the weather), practical function(e.g. terms for things that makes a car work), linguistic function (e.g. apology, request, demand), similarity (e.g. warm, hot, tropical)or opposition(e.g. friendly/unfriendly) Association /elaboration: is associating concepts already exist in memory with new language information, for instance, assigning names of well-known brands with the corresponding business sector like (Manufacturing /TOYOTA, transportation /Turkish airlines...etc.). and placing newly heard or written words into a context such as examples in spoken or written sentences.

Applying images and sounds is subdivided into four types; using imagery, semantic mapping, keywords, and representing sounds in memory. Using Imagery representations means relating new language information to concepts settled in memory by means of meaningful visual imagery. Semantic mapping involves making arrangements of highlighted key concepts and relationships creating a semantic map in a diagram. The key concepts (in a form of words) are connected with related concepts by means of drawing lines and arrows. Semantic maps for Baumann et al., (2003)and Heimlich and Pittleman (1986) are to assist students to develop linkage among words and increase the learning of vocabulary words (For example, by writing an example, a non-example, a synonym, and an antonym).

Using keywords then is applied by using auditory and visual links to remember a new word and finally representing sounds in memory by remembering new information according to its sound. For example, by linking an abstract word with a known object like the word "bonus", a student will draw a picture of extra money paid for an employee for good performance.

Reviewing well can be accomplished through the strategy of structured reviewing. Oxford (1990:66) stressed that reviewing well entails a systematic review when long-term memory is the purpose of any learning to be stored. After regular intervals, the review 
is conducted leading to the familiarity of the word usage accruing automatically. Employing Action means involvement of meaningful actions such as physical response instigating the senses and using mechanical techniques with cards, letters, words, etc., provide the kinesthetic mode of learning of language for the improved acquisition of vocabulary. Associating meaningful activities, for example, physical reaction triggers the senses by using mechanical strategies with letters, cards, words, etc. This kinesthetic method of learning language improves vocabulary acquisition Oxford (1990:69).

\subsubsection{Thompson (1987) Mnemonics}

Thompson (1987:44) on the other hand emphasized the physical approach to distinguish five divisions of mnemonics which mostly depend on physical cognition; linguistic mnemonics, spatial mnemonics, visual mnemonics, the physical response method, and verbal elaboration methods. Instances of linguistic mnemonics include; the peg word method and the keyword method. The peg word method depends on reviewing irrelevant things by connecting them with some previously-stored "pegs". They can be rhyming words or digits like the popular rhyme "one is a bun, two is a shoe, three is a tree ... and so on" Learners can frame an image of the first word in the list of the targeted language and related it to a "bun." For instance, if the target word to be learned is 'dog', the student can shape an image of a dog eating a bun. He suggested that in learning second language vocabulary, students ought to abstain from using peg words from their first language and they should make the "blending" totally in the SL (Thompson,1987:45). The keyword method was originally created by Atkinson (1975). It depends on setting up an imaginary connection between the new $\mathrm{L} 2$ word and a word in the student's first language that may have a sort of similarity. Like the Spanish word pan which means "bread". It is acoustically linked with the English word "pan" and easy to imagine a loaf in a pan (ibid:44). Figure 2. below shows Thompson's mnemonics.

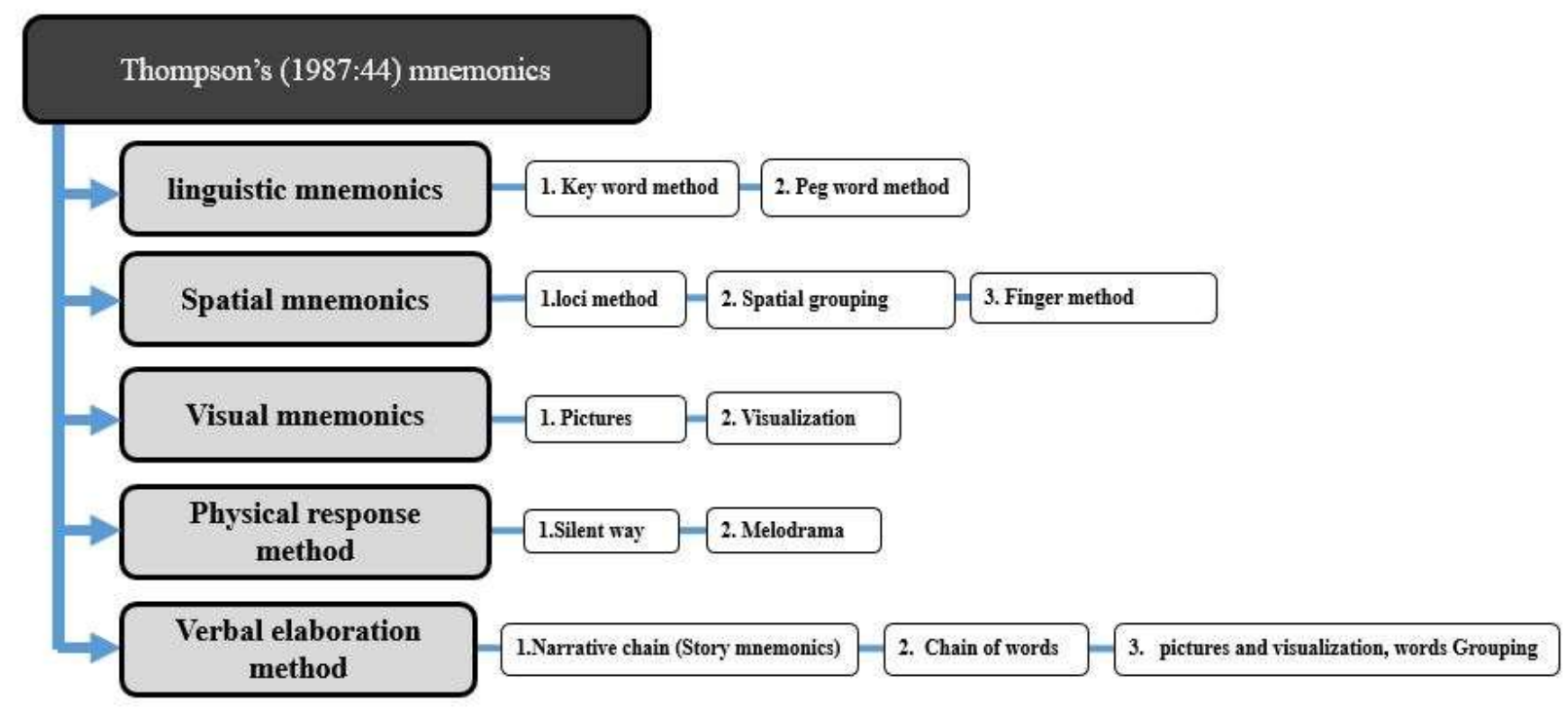

Note: Figure 2.: by Thompson, J. (1978). Memory in Language Learning. In A. Wenden \& J.Rubin (Eds.), Learner Strategies in Language Learning (pp.43-56). Englewood Cliffs, NJ: Prentice-Hall.

Thompson (1987:45) identified three types of spatial mnemonics: the loci method, spatial grouping, and the finger method. Thousands of years ago, Romans used the loci method to memorize speeches (1987: 44, 45). This method depends on images of objects in certain places. The person memorizes the form of buildings, the order of stores on the street, or any geographical entity made up of a number of discrete locations using this technique. When attempting to recall a group of items, the person 'walks' through these loci in their mind, committing an item to each one by establishing a picture between the item and any feature of that loci. Things are retrieved by 'walking' through the loci, which allows the latter to activate the required items. This technique's efficacy has been extensively proven in enhancing memory (Ross and Lawrence 1968, Crovitz 1969, 1971, Briggs, Hawkins, and Crovitz 1970, Lea 1975) and low interference has been observed with its use (ibid,1987:45).

Moreover, spatial grouping alludes to "rearranging" vocabulary to make "patterns", of a triangle for instance arranging L1 words in such a particular pattern to support both immediate and delayed recall of data (Ibid: 45).

The third type of spatial mnemonics is the "finger" strategy, where students associate every word supposed to be learned with a finger. Visual strategies are the fourth in Thompson's (1987:45) mnemonics which come in two structures: pictures and visualization. He referred to studies that investigated that students who matched L2 vocabulary with pictures had the ability to recall better than 
those who combined them with equivalents in their L1. Nonetheless, in utilizing pictures, vocabulary items, or any data "visualized" in the brain as opposed to utilizing an actual picture (Thompson, 1987: ibid). Concerning the physical response technique, it alludes to physically "enacting" the new data.

Thompson (1987:43) stresses the significance of mnemonic techniques is vivid in language learning in which memorization and retrieval are the base. He added that these techniques provide learners with faster learning and better recalling since they enhance the integration of new information with existing cognitive units because they facilitate retrieval cues. They are applicable to learning differences between individuals and most users enjoy using them.

\subsubsection{Gu and Johnson's (1996) Learning Strategies}

Gu and Johnson (1996) proposed two major learning categories; Learning Strategies and Vocabulary Learning Strategies(VLS). For them, learning Strategies are classified into four subdivisions namely; Metacognitive, Cognitive, Memory, and Activation Strategies. VLS is subdivided into seven strategies; Metacognitive Regulation, Guessing Strategies, Dictionary Strategies, Note-taking Strategies, Rehearsal Strategies, Encoding Strategies, and Activation Strategies. Metacognitive Strategies include strategies of selfmotivation and selective awareness. When second language learners are engaged in strategies like selective awareness, they will be aware of the types of words essential for their learning to provide an adequate comprehension of a passage. Cognitive strategies comprise skillful dictionary use, guessing strategies, and note-taking strategies. Background knowledge is the base of learners' knowledge who use guessing strategies as well as those who use linguistic aids like guessing the word's meaning from the grammatical structure of the sentence. Memory Strategies: are subdivided into two categories; rehearsal and encoding strategies. Rehearsal strategies comprise: using the word list, oral repetition, and visual repetition. Encoding strategies, involves auditory aids (through repetition), imagery (constructing mental image when learning new information), association (Like Luci method; associating a familiar location with new data learned), visual encoding (converting new information into mental pictures), semantic encoding ( by processing the input or meaning in a context like remembering a meaning from the sound of the word), and contextual encoding (context-dependent meaning) in addition to word-structure (like analyzing a word according to stem, prefixes, and suffixes.) (Gu and Johnson's, 1996:82). Activation Strategies include the actual use of newly acquired words in various contexts like forming sentences by using the newly learned words. Figures 3. and 4. show these categories and their sub-categories.

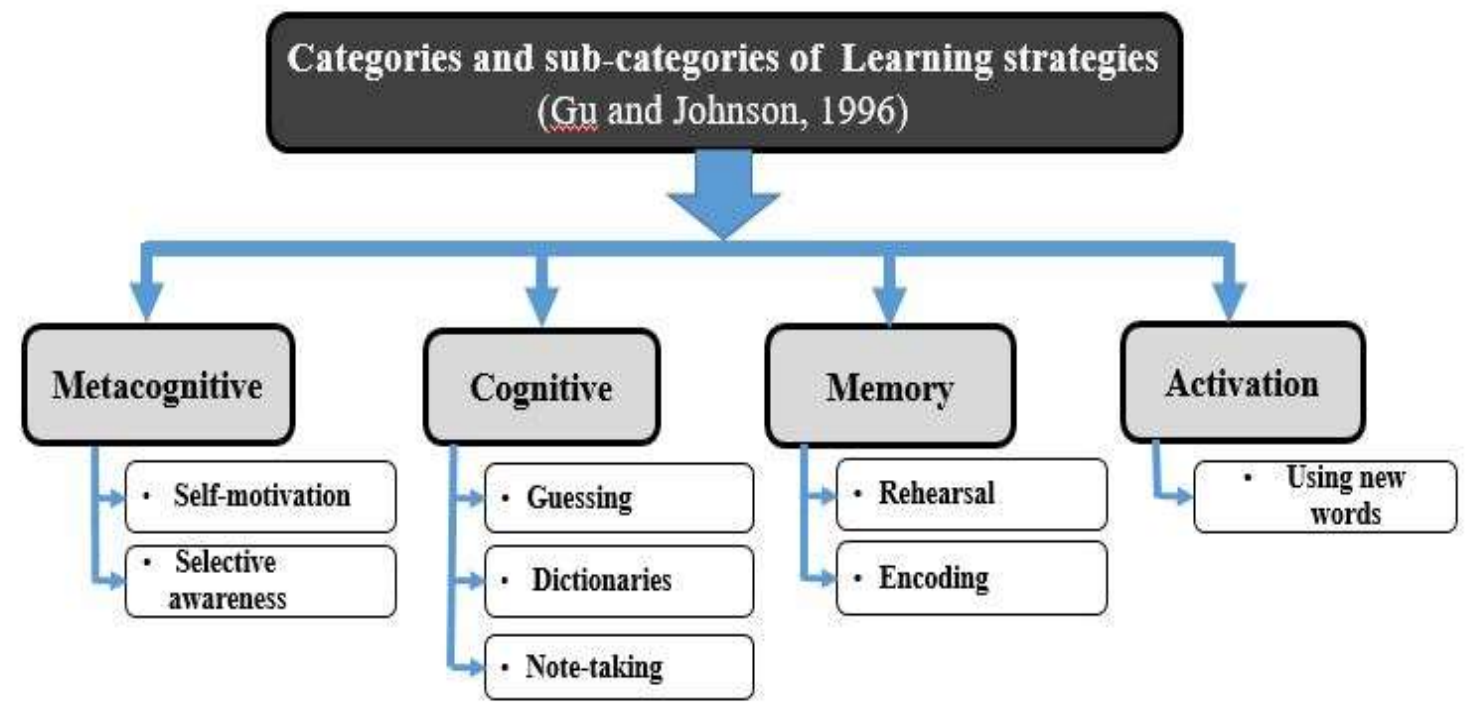

Note: Figure 3.: by Gu, Y., \& Johnson, R. K. (1996). Vocabulary language learning strategies and language outcomes. Language Learning, 46 (4), 643-679. 


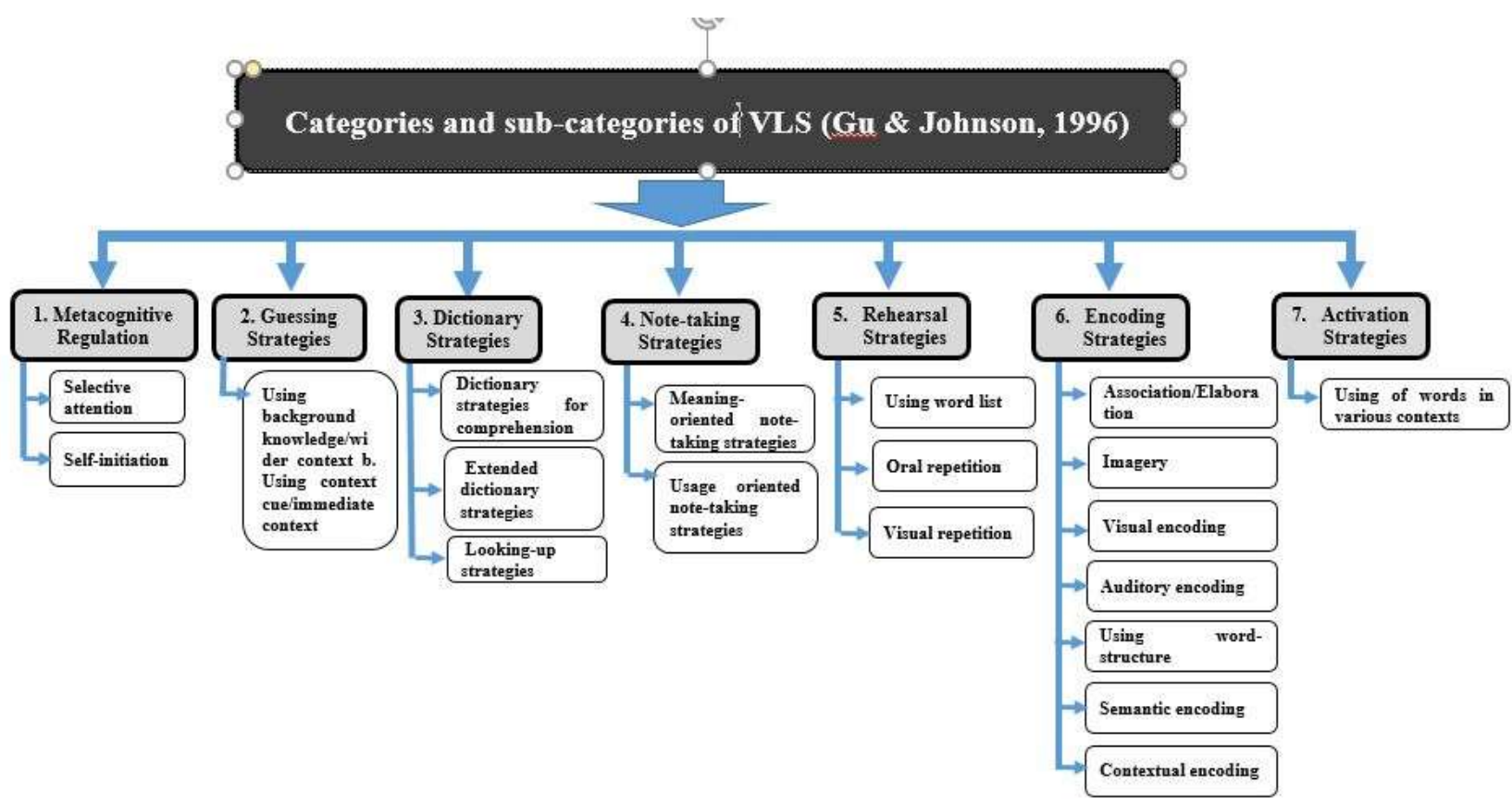

Note: Figure 4. by Gu, Y., \& Johnson, R. K. (1996). Vocabulary language learning strategies and language outcomes. Language Learning, 46 (4), 643-679.

Figures 3. and 4. above summarize categories and sub-categories of learning strategies and Vocabulary Learning Strategies VLS by $\mathrm{Gu}$ and Johnsons, 1996 who worked also on a substantial list categorized according to vocabulary learning strategies like; guessing, metacognitive regulation, dictionary, and note-taking strategies.

\subsubsection{Macaro's (2000) Classification of Memory Strategies}

Macaro (2001) distinguished two groups of MS. The first comprises strategies that are called" positive cognizant exertion" for language to be stored in memory. Macaro (2001) summarized them as follows:

1. At home, words are rehearsed loudly by uttering them for all to hear.

2. Learning vocabulary within a framework that is suitable for students (such as: to see the word, hide it, say it, write it down, then check it).

3. Creating mental affiliations when trying to remember strange words.

4. Utilizing melodies, rhymes, or memory aides into language,

The second arrangement of MS encompasses techniques used to rehearse by "quick creation" then storing in the long-term memory. They are summed up as follows:

1. When learning vocabulary in the class, rehearsing words to oneself is preferred.

2. Thinking about words and quietly rehearsing them Macaro (2001:119).

\section{Vocabulary Learning Strategies (VLS)}

Vocabulary learning strategies can be defined as abilities or activities aiming to enhance word comprehension and storage, as well as to assist word retrieval from memory and usage in appropriate settings. Oxford (1990:8) defined VLS as "specific measures taken by the learner to make learning easier, faster, more pleasurable, more self-directed, more effective, and more transferable to other settings". They are defined by O'Malley and Chamot (1990:1) as "unique ideas or behaviors that humans use to grasp, learn, or retain new knowledge." So, words' knowledge is defined as knowing how to spell them, to pronounce them, their collocation as well as their appropriateness (Nation, 1990). In this sense, through a long term researcher of second and foreign language made a lot of attempts to develop a taxonomy of vocabulary learning strategies and provided identifications and classifications to the strategies utilized by language learners resulting in different taxonomies, often as a part of research into the learners' strategy. Instances of such classifications are made by Schmitt (1997) who developed an elaborated taxonomy arranged in accordance with Oxford's (1990) social, memory, cognitive, and metacognitive divisions and Nation's (2001) consolidation distinction. Gu and Johnson (1996), as has previously mentioned, provided a fundamental list classified into concepts about vocabulary learning; 
metacognitive regulation, using dictionaries strategies, note-taking strategies, guessing strategies, memory strategies (like rehearsal and encoding), and activation strategies.

\subsection{Schmitt (1997) Taxonomies of Vocabulary Learning Strategies}

Schmitt suggested vocabulary-specific taxonomy. His categorization classifies 58 VLS into two extensive classes and six types of strategies. The top class is discovery strategies which encompass determination strategies for finding another meaning for the word without assistance from others and social techniques that include asking educators or colleagues for the meaning or translation. The second class of Schmitt's1997 class is consolidation strategies, which include what is vital for remembering a word after introducing it. These strategies are divided into four types: metacognitive, which includes decision-making with the conscious learning process; social strategies, such as exercising and applying the meaning in a group of learners or communicating it with L1 speakers; cognitive strategies, like the verbal and written repetition; and memory strategies, or mnemonics as sometimes referred to, which indicates linking the word with previous data using grouping, association or imagery. By these strategies, as shown in Figure 5. , Schmitt (1997) developed an established system that comprises vocabulary learning strategies that "has the advantage of being organized around an established scheme of learning strategies" (Segler, Pain, and Sorace, 2002: 413). Thus, his taxonomy of VSL is considered as the tool to examine students' strategy use.

\section{Vocabulary Learning Strategies, Schmitt (1997)}

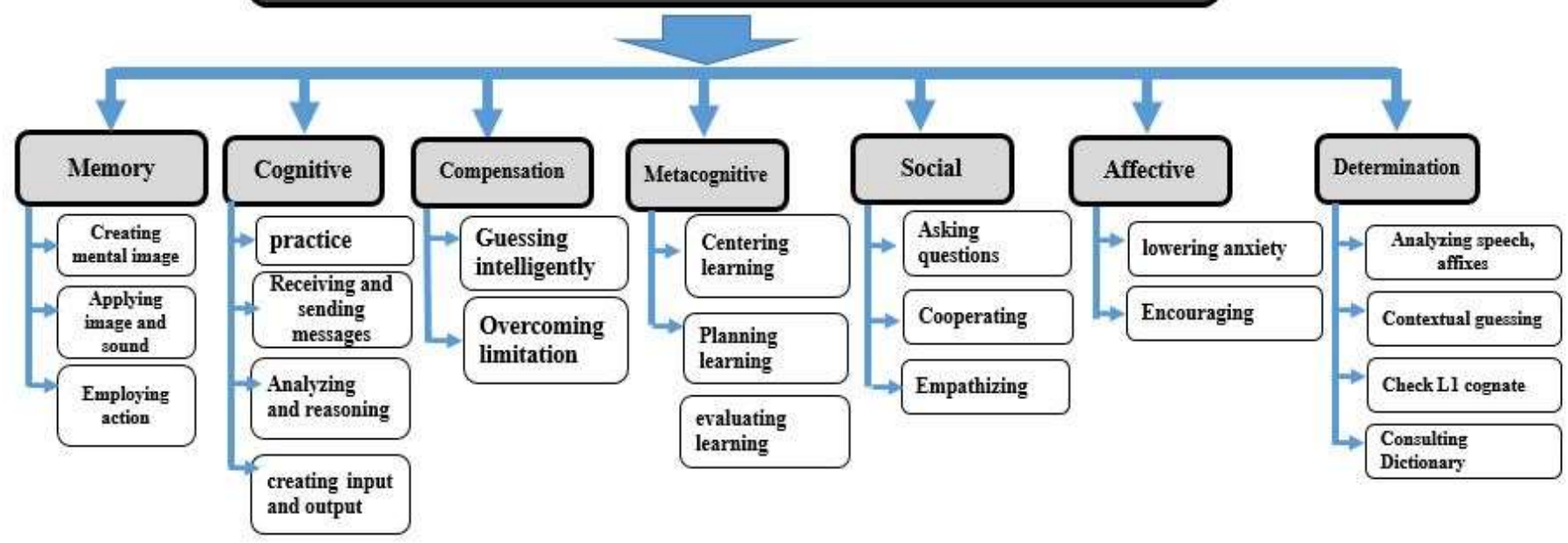

Note: Figure 5. By Schmitt, N. (1997). Vocabulary learning strategies. Vocabulary: Description, acquisition and pedagogy, 199227.

In response to the lack of a comprehensive vocabulary list Schmitt (1997) categorized memory strategies into six subdivisions: learning new words associated by pictures or imagery; connecting the word with relevant words; linking the word with irrelevant words; grouping; using the word's phonological or orthographical form "the keyword method"; in addition to others, like adding affixes or roots and using physical action. These strategies help the learner connect the new word meaning with the already known knowledge. The reason for that is merging the new vocabulary with the existing knowledge which learners have. So, deeper processing occurs thereby by creating a durable memory trace that results in better retention than rote memorization (Craik \& Lockhart, 1972).

\subsection{Nation's (2001) Vocabulary Learning Strategies}

Nation (2001) on the other hand, classified VLS into three general classes emphasizing the context as a source of information about a word. It is found in various aspects that are related to knowing a word namely; the medium, the written form, the word parts, the meaning, reference, grammar, collocations, and word use constraints. 


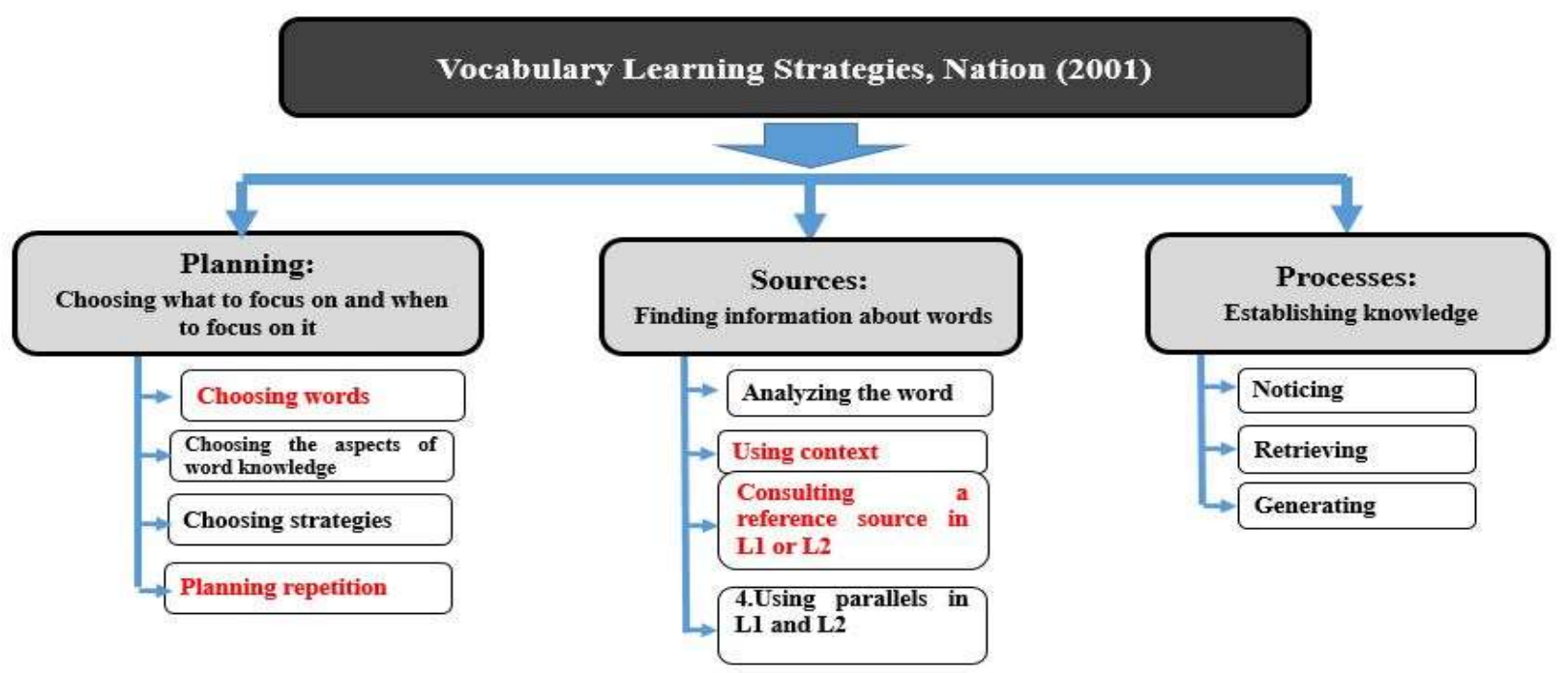

Note: Figure 6. By Nation, I.S.P (2001). Learning Vocabulary in Another Language. Cambridge University Press.

Figure 6. shows Nation's (2001) classification that falls into a general class of strategies namely: planning', 'source' and 'processes', each of which includes subcategories. The first is planning which means deciding the material to be learned with the time specified for that as well as the times' vocabulary items are focused on. This category encompasses choosing words, choosing aspects of word knowledge and choosing strategies, planning repetition. Choosing words involves the type of vocabulary to focus on; either highly frequent, academic, technical or low frequent. Choosing the aspects of word knowledge refers to identifying the words' meaning. Choosing strategies is finding the most appropriate strategy utilized in learning vocabulary as well as planning the way and the time of repetition. The second is Sources, where information about words should be given. Sources include analyzing the parts of the word of speech), identifying the context in which the word should be found, consulting a reference source in the L1 or L2, and using parallels in L1 and L2. The third group of strategies is Processes by which knowledge about words is established in manipulating noticing, retrieving, and generating. This category includes strategies of noticing, retrieving and generating receptive/productive information, oral/visual data, in context/decontextualized vocabulary. In addition to all strategies mentioned, Nation (2001) added instructional strategies such as activating viewpoints, linking new knowledge with previous ones by presenting visual examples of words, analyzing, semantic mapping, or using grids and scales. Moreover, creating contexts, sentences containing the word, collocations, and mnemonic strategies like the keyword or peg word techniques or using the word in various contexts through the four skills of language; listening, speaking, reading, and writing.

\subsection{Brown \& Payne's (1994) Model of Vocabulary Learning}

Finally, Brown and Payne (1994) (cited in Fan, 2003:223) proposed a model of five important processes in vocabulary learning... The steps comprise:

a. having resources for learning new words,

b. obtaining a distinct image, either visual or auditory or both, of the new words' forms, learning the meaning of the words,

c. establishing a strong memory link between the forms and meanings of the words;

d. and employing the words.

According to Fan (2003), all vocabulary learning procedures are related to these five processes to some extent.

When investigating learners' technique utilization, some studies (e.g., Fan, 2003; Gu \& Johnson, 1996; Nation, 1990; Schmitt, 1997; Stoffer, 1995) sought to build a classification system for a comprehensive list of vocabulary acquisition strategies. Stoffer created a 53-item Vocabulary Learning Strategy Inventory (VOLSI), which was given to 707 University of Alabama undergraduates. Using factor analysis, those items might be further categorized into nine categories: strategies including authentic language use, strategies including creative activities, mental linkage methods, memory strategies, visual/auditory strategies, physical action strategies, anxiety management strategies, word organizing strategies, and self-motivation strategies.

\section{Conclusion}


The discussion above shows that scholars have classified language learning strategies into different taxonomies. All of these taxonomies involve MS in addition to other types of strategies. It is obvious that MS share a lot of similarities in the general aspects but the difference is in the terminologies like MS, VS, mnemonics, applying images and sounds, visual mnemonics / verbal method, association spatial mnemonics..., etc. The dispute is on the types of divisions and subdivisions they follow as in Oxford (1990) and of Thompson (1987). The case is remarkable with Gu and Johnson (1996). It can be noticed that they have related learning strategies including MS with VLS. Macaro (2001) divisions differ only in applying them at home and in class with slight differences in achievement. Notably, VLS encompasses either MS as it is termed in Schimitt's (1997) taxonomies or other strategies in enhancing memory like planning repetition, retrieving, using context...etc., as in Nation's (2001).

As for Brown and Payne's (1994) model, it can be applied in every setting and context; class or home, a group working or individually with either applying MSs or VLS or even both.

It can also be concluded that:

1. Through centuries continuous studies of MSs occupy an overriding stature. Thus, they are emphasized by a numerous number of not only linguists but also psychologists.

2. The principal MSs work, as agreed upon, is simply and basically depends on reducing the amount of information when human tries preserve information in mind to remember it when needed. To improve learning, Schallers suggested adopting various techniques, strategies, aids, and tools (as they term them differently).

3. By different studies and empirical experiments on MSs resulting in different theories and models carried out by researchers, efforts had been spent to enhance data retrieval in the learner's brain. Consequently, this will help the academic and educational process of language learning in general and vocabulary learning in particular. Thus, multiple types of strategies were suggested like: grouping, associations, semantic mapping, reviewing well, using mechanical techniques Oxford (1990), types of mnemonics (linguistic, spatial, visual, physical, verbal) by Thompson (1987), learning strategies and vocabulary learning strategies by Gu and Johnson (1996).

4. Teachers and learners could take benefit from these strategies in accordance with the nature of their society, class setting structure, previous knowledge, and other factors.

\section{References}

[1] Baddeley, A. D. (1999). Essentials of human memory. Psychology Press: East Sussex, UK.

[2] Bower, G. H., Clark M. C., Lesgold A. M., \& Winzenz, D., (1969). Hierarchical Retrieval Schemes in Recall of Categorized Word Lists.Journal of Verbal Learning and Verbal Behavior,8(3),323-343,doi:10.1016/s0022-5371(69)80124-6.

[3] Coxhead, A. (2013). Vocabulary in ESP. In Paltridge, B., \& Starfield, S. (Eds.), The handbook of English for specific purposes (pp. 115-132). West Sussex, UK: Wiley Blackwell.

[4] Dudley-Evans, T., St John, M. J., \& Saint John, M. J. (1998). Developments in English for specific purposes: A multi-disciplinary approach. Cambridge university press.

[5] Fan, H. Y. (2003). Operator ordering in quantum optics theory and the development of Dirac's symbolic method. Journal of Optics B: Quantum and Semiclassical Optics, 5(4), R147.

[6] Gu, Y., \& Johnson, R. K. (1996). Vocabulary language learning strategies and language outcomes. Language Learning, 46 (4), 643-679.

[7] Harris, J. E. (1980). Memory aids people using Two interview studies. Memory \& Cognition, 8(1), 31-38.

[8] Heuer, R. J. (1999). Psychology of intelligence analysis. Center for the Study of Intelligence.

[9] Johns, A. M., \& Dudley-Evans, T. (1991). English for specific purposes: International in scope, specific in purpose. TESOL Quarterly, 25(2), 297314.

[10] Lord, R. G., \& Kernan, M. C. (1987). Scripts as determinants of purposeful behavior in organizations. Academy of Management Review, 12(2), 265-277.

[11] Macaro, E. (2001). Learning strategies in second and foreign language classrooms. London: Continuum.

[12] Nation, I.S.P (2001). Learning Vocabulary in Another Language. Cambridge University Press.

[13] Oxford, R. L. (1990). Language learning strategies: What every teacher should know. Boston: Heinle and Heinle Publishers.

[14] Oxford, R. (2001). Integrated Skills in the ESL/EFL Classroom. ERIC Digest.

[15] Ross, J., \& Lawrence, K. A. (1968). Some observations on memory artifice. Psychonomic Science, 13(2), 107-108.

[16] Rubin, J. (1987). Learner strategies: Theoretical assumptions, research history, and typology. In Wenden, A.L., \& Rubin, J. (Eds.), Learner strategies in language learning (pp.15-30). New Jersey: Prentice-Hall.

[17] Rupley, W. H., Logan, J. W., \& Nichols, W. D. (1998). Vocabulary instruction in a balanced reading program. The Reading Teacher, 52(4), 336346.

[18] Schmitt, N. (1997). Vocabulary learning strategies. Vocabulary: Description, acquisition and pedagogy, 199227.

[19] Schmitt, N. (2007). Current perspectives on vocabulary teaching and learning. In International handbook of English language teaching (pp. 827-841). Springer, Boston, MA. 
[20] Schmitt, D. (2002). Learning Vocabulary in Another Language. I.S.P. Nation. ELT Journal, 56(1), 91-93.

[21] Schmitt, N. (2008). Instructed second language vocabulary learning. Language teaching research, 12(3), 329-363.

[22] Schmitt, N. (2000). Vocabulary in language teaching. Cambridge: Cambridge University Press.

[23] Snow, B., \& Burns, M. (2000). Griffin, 1998. Report of the National Reading Panel. Teaching children to read: an evidence-based assessment of the scientific research literature on reading and its implications for reading instruction.

[24] Thompson, J. (1978). Memory in Language Learning. In A. Wenden \& J.Rubin (Eds.), Learner Strategies in Language Learning (pp.43-56). Englewood Cliffs, NJ: Prentice-Hall.

[25] Woodward-Kron, R. (2008). More than just jargon - the nature and roles of specialist knowledge in learning disciplinary knowledge. Journal of English for Academic Purposes, 7, 234-249.

[26] Zimmerman, B. J. (1998). Academic studying and the development of personal skill: A self-regulatory perspective. Educational psychologist, 33(2-3), 73-86. 